\title{
Illicit drugs and their impact on cardiovascular pathology
}

\author{
ELISABETA BĂDILA $\breve{~}^{1,2}$, MIHAELA HOSTIUC ${ }^{1,2}$, EMMA WEISS $^{1,2}$, DANIELA BARTOŞ ${ }^{1,2}$ \\ 1“"Carol Davila" University of Medicine and Pharmacy, Bucharest, Romania \\ 2"Floreasca" Emergency Clinical Hospital, Bucharest, Romania
}

\begin{abstract}
The use of illicit drugs has dramatically increased during the past years. Consequently, the number of presentations at the emergency departments due to the adverse effects of the illicit drugs has also increased. This review discusses the cardiovascular effects of cocaine, opiates and opioids, cannabinoids, amphetamines, methamphetamines and hallucinogens as we consider that it is essential for a clinician to be aware of them and understand their mechanisms in order to optimize the therapeutic management.
\end{abstract}

Key words: illicit drugs, cocaine, cardiovascular effects.

\section{INTRODUCTION}

Whether light or dangerous, illicit drugs are increasingly used particularly among the young population. Statistics show a $10.9 \%$ use for LSD and an $11 \%$ for MDMA (Ecstasy) [1]. Statistics also show that $37 \%$ to $49 \%$ of the young population has already used hallucinogenic substances on at least one occasion [1]. In most cases, the use of hallucinogenic drugs eventually leads to usage of more dangerous drugs such as cocaine, morphine or heroine. Apart from their important social impact, such behaviors also have adverse medical effects on the users.

This review discusses the cardiovascular effects of cocaine, opiates and opioids (morphine, heroine and methadone), cannabinoids (marijuana, hashish), amphetamines, methamphetamines and hallucinogens (lysergic acid diethylamide - LSD,3,4-methylenedioxymethamphetamine - MDMA better known as "ectasy", etc.).

\section{COCAINE}

Cocaine is an alkaloid extract, naturally obtained from Erythroxylon coca, a plant originating in South America. Its water soluble hydrochloride salt is absorbed on mucous surfaces. Cocaine has both acute and chronic cardio toxicity. It exerts its cardiotoxicity both directly and indirectly.

Direct toxicity is manifested first of all at the site of the endothelium. Endothelial dysfunction is secondary to the increased endothelin and to the decreased nitric oxide production in endothelial cells, thus leading to vasoconstriction [2, 3]. Cocaine also induces structural defects of the endothelial barrier through increased permeability for lowdensity lipoproteins, increased leucocyte migration and enhanced expression of endothelial adhesion molecules [4]. All these structural changes promote an accelerated atherosclerosis.

Cocaine induces a procoagulant status due to the activation of platelets, increased platelet aggregation [5], increased release of $\alpha$-granules from platelets [6], increased PAI-1 (plasminogen activator inhibitor) activity and increased levels of fibrinogen and von Willebrand factor [7, 8].

Cocaine abuse also results in cardiac conduction abnormalities due to sodium channels blockage and due to the blockage of rapid repolarizing inward potassium channels (Ikr) coded by the $h E R G$ (human-ether-related-a-go-go channel) gene [9]. This leads to a prolonged QT interval and enlarged QRS complexes, resulting in an increased risk for malignant arrhythmias. The direct toxic effect of cocaine on the myocardium results in decreased contractility, large complex arrhythmias, bradycardia, and arterial hypotension.

Indirect toxicity is a consequence of the excess of catecholamine levels. Cocaine blocks the reuptake of norepinephrine, dopamine and serotonin at the site of preganglionic neurons. This causes vasoconstriction and an increase in oxygen demand, and, in case of chronic abuse, myocyte apoptosis followed by cardiac remodeling [10].

Cocaine also interacts with various genes. For example, it activates the gene for calmodulin kinase II, which increases the release of calcium from the endoplasmic reticulum. Consequently, intracellular calcium levels increase and this causes 
cardiomyocytesto hypertrophy, eventually resulting in the development of heart failure.

Cocaine users have an elevated concentration of circulating catecholamine levels. The catecholamine having a significant effect on the heart is norepinephrine, which acts as a neurotransmitter. Norepinephrine is released into the synaptic cleft when an impulse is transmitted. Impulse transmission stops only when norepinephrine is pumped back into the presynaptic nerve ending. Cocaine blocks the re-uptake of norepinephrine and, in this way, its effects are exacerbated. Un-metabolized epinephrine flows into the systemic circulation and acts as a hormone, binding to its receptors from different organs. A mild stimulation of $\beta 2$-receptors in the heart improves cardiac function, whereas excessive stimulation induces dilated cardiomyopathy. Overstimulation of adrenergic receptors results in myocyte apoptosis and in an exaggerated remodeling process [10].

In cocaine users, an increased production of atrial natriuretic factor and the activation of reninangiotensin system have also been noticed [10].

The existent excess of catecholamines in case of acute or chronic cocaine abuse induces various histological changes in the myocardium. They are easily distinguished from those produced by ischemia. The best-known modification is contraction band necrosis. It is also known as coagulative myocytolysis or myofibrillar degeneration. This type of lesion appears in the reperfusion area of the myocardium after angioplasty or after repeated defibrillations. The difference between contraction band necrosis induced by ischemia and contraction band necrosis secondary to catecholamine excess can be observed by analyzing their distribution. In the latter, these lesions are distributed between normal cells [10].

Hypertrophic cardiomyopathy has also been noticed in cocaine users, as some patients have hearts weighing over $1200 \mathrm{~g}$ due to calmodulin kinase II stimulation secondary to the excess catecholamine levels [10]. In these cases, the nuclei of hypertrophic myocytes become elongated and squared. Microvascular disease is also present. Hypertrophy of the capillary wall is evident as myofilaments are destroyed as a result of catecholamine-induced necrosis which form eosinophilic clumps. What is more, mitochondria are translocated and have distorted shapes [10].

Even though these histological changes have been described in cocaine abusers they may also occur in other circumstances such as secondary to other toxic substances (amphetamines, epinephrine, etc.) or to other pathologic situations (myocardial infarction, cerebral hemorrhage, cerebral death, etc.).

Table 1

Histological differences between ischemic and catecholamine necrosis

\begin{tabular}{ll}
\hline \multicolumn{1}{c}{ Ischemic necrosis } & \multicolumn{1}{c}{ Catecholamine necrosis } \\
\hline Affects many cells from the area supplied by a single vessel & Focal lesion: necrotic cells surrounded by normal cells \\
\hline Unchanged myofilaments & Destroyed myofilaments, forming eosinophilic clumps \\
\hline Mitochondria with uniform size & Mitochondria with distorted shapes \\
\hline
\end{tabular}

\section{CLINICAL PICTURE}

Cocaine increases myocardial oxygen demand as a result of the increased heart rate and increased blood pressure. These effects are dose-dependent and result from $\alpha$-adrenergic stimulation. Cocaine decreases the oxygen supply via vasoconstriction, thus reducing coronary flow and inducing microvascular disease which will further narrow coronary arteries diameter. Long-term cocaine use leads to endothelial dysfunction at the site of the coronary arteries making them more sensitive to catecholamine mediated vasoconstriction. Cocaine produces microvascular disease, which is often associated with thrombosis. It also induces both systolic and diastolic dysfunction, arrhythmias and accelerated atherosclerosis. Cocaine decreases contractility and ejection fraction due to the blockage of sodium and potassium channels in the myocardium. Prolonged use of cocaine is associated with left ventricular hypertrophy and prolonged deceleration time. Cocaine prolongs PR interval, QRS complex and QT interval.

Clinical manifestations of cocaine abuse are various and include: myocardial ischemia or myocardial infarction, myocarditis, cardiomyopathy, arrhythmias, coronary artery aneurism, aortic dissection, stroke.

\section{Chest pain}

Any patient with chest pain and recent cocaine use should be evaluated for myocardial ischemia/infarction and aortic dissection. The risk of myocardial infarction is increased 24 fold in the first hour after cocaine use [8]. 
Acute coronary syndromes are the most common clinical manifestation of cocaine users. It is difficult to evaluate their real incidence because many users are cigarette smokers and/or have other cardiovascular risk factors [11]. Cocaine users with acute coronary syndromes may associate dyspnea and diaphoresis and rarely pleuritic pain, nausea, palpitations, syncope and vomiting. These manifestations often appear only a few hours after cocaine use, the highest risk being during the first hour.

The electrocardiogram is difficult to be interpreted in such patients because of the relative high incidence of repolarization abnormalities and left ventricular hypertrophy. Even so, $84 \%$ of cocaine users with chest pain have ECG abnormalities. A pathological Q wave can be observed in approximately $50 \%$ of cases. There is an equal distribution between anterior and inferior wall myocardial infarction [8].

As far as cardiac biomarkers are concerned, troponin remains specific for myocardial injury in case of a myocardial infarction in cocaine users, while other biomarkers such as myoglobin, creatinkinase and its cardiac specific isoform creatinkinase-MB, may be elevated even in the absence of myocardial infarction if the patient also associates muscle trauma or rhabdomyolysis, or when the blood sample is taken after intense physical activity. The cardiac biomarkers have a low specificity in cocaine users compared to nonusers [8]. Therefore, the preferred biomarker remains troponin as it is not influenced by recent cocaine use.

The angiography in patients with myocardial infarction reveals one-vessel or two-vessel disease in $31-66 \%$ of cases, tree-vessel disease in $13-15 \%$ of cases, normal coronary arteries in $18-45 \%$ and thrombus without obstructive disease in $24 \%$ of cases $[8,12,13]$.

The complications in patients with myocardial infarction and cocaine abuse are: heart failure in $7 \%$ of cases, sustained ventricular tachycardia in $4 \%$ of cases, higher in-hospital mortality (8.3 versus $0.8 \%)[8,14]$. These complications often occur within the first 12 hours after the onset of chest pain.

Aortic dissection must also be taken into consideration in cocaine users with chest pain. It occurs more often in cocaine users with untreated or uncontrolled arterial hypertension. Cocaine use is involved in $0.5-1.8 \%$ of cases of patients with acute aortic dissection [15-17].
Coronary artery aneurisms are relatively frequently noticed in cocaine abusers who undertake coronary angiography (30\%) compared to nonusers, in whom their incidence reaches only $1.5 \%$. Coronary artery aneurisms may become a potential cause of myocardial infarctions [8].

\section{Myocarditis and cardiomyopathy}

Myocarditis is common among cocaine users reaching an incidence of $20-30 \%$. Its exact pathological mechanism is not known. It is supposed that a hypersensibility reaction to catecholamine induced toxicity is involved. In case of early diagnosis, myocarditis may be completely reversible under treatment. Drugs with $\beta$-blocker activity are contraindicated in cocaine users [8].

Dilated cardiomyopathy has been described in cocaine users but an exact cause-effect relation between them has not been established yet. Factors most probably involved are: the toxic effect of cocaine on the myocardium (myofilaments destruction, interstitial fibrosis), catecholamine excess (which causes contraction band necrosis), infectious agents with cardiac tropism and chronic ischemia. Cessation of cocaine use can lead to complete remission of myocardial dysfunction.

\section{Arrhythmias and conduction disturbances}

These are not uncommon in cocaine abusers, but the arrhythmogenic effect of cocaine is not completely understood. The excess catecholamine levels induced by cocaine use can explain the exacerbation of arrhythmias and conduction disturbance in certain circumstances. The most frequent arrhythmias are sinus tachycardia, supraventricular tachycardia and rarely atrial fibrillation. Cocaine acts through its local anesthetic effect, blocking the sodium channels the same way as class I antiarrhythmic drugs: prolongs repolarization, prolongs the QT interval which predisposes to ventricular tachycardia or torsades de pointes (a major cause of sudden death). Other factors that may predispose to arrhythmias in cocaine users are: altered automatism by direct toxic effect, altered autonomous balance secondary to catecholamine excess, ischemia that causes an electrical inhomogeneity and an anatomic background for reentrant arrhythmias.

\section{Endocarditis}

Endocarditis is a frequent complication among cocaine users. It has been noticed that a quarter of 
drug abusers with fever have endocarditis, the tricuspid valve being the most commonly affected heart valve. The common risk factors are: frequent injections, sometimes with non-sterile needles, and direct effects of cocaine (endothelial damage and procoagulant status) $[8,18]$.

\section{Vascular manifestations}

Other vascular manifestation in cocaine users refer to mesenteric ischemia, acute peripheral ischemia, renal infarction and erectile dysfunction. These complications occur due to the accelerated atherosclerosis and to the endothelial dysfunction [8].

In case of acute cocaine use an acute hypertensive crisis may occur secondary to the excess catecholamine levels. Cocaine use has not been related to chronic hypertension [19].

\section{Myocardial ischemia}

The treatment of myocardial ischemia, regardless of its type, in cocaine users, uses the same therapeutic principles and doses. The only exception comes from the contraindication of using drugs with $\beta$-blocking activity as they are not recommended in the acute phase of the coronary syndrome in cocaine users with recent abuse [8]. As far as benzodiazepines are concerned, diazepam administration prevents elevation of blood pressure levels, of heart rate, acidemia and hyperthermia [20]. Benzodiazepines also relieve chest pain in a similar fashion to nitroglycerin. Diazepam should be administered intravenously. If this is not followed by pain relief and there is evidence of myocardial damage other additional therapies are needed. Nitroglycerin administered sublingually or intravenously attenuates chest pain in approximately one half of cocaine users. Nitroglycerin reverses coronary vasoconstriction induced by cocaine [21]. It should be administered in patients with persistent chest pain after diazepam administration [8].

Calcium channel blockers are used as second line therapy for hypertension and coronary spasm. Short-acting calcium channel blockers (nifedipine) should not be used. Verapamil is indicated. Usually calcium channel blockers are indicated in patients with ischemic chest pain and ST segment elevations or depressions [8].

Aspirin is an important therapeutic agent for the treatment of chest pain in cocaine users. Cocaine predisposes to thrombus formation secondary to platelet activation, increased platelet aggregation and increased thromboxane release.
Other antiplatelet agents such as clopidogrel and glycoprotein IIb/IIIa or heparin can also be used [8].

Phentolamine is a non-selective $\alpha$-antagonist used for hypertensive emergencies and it may be beneficial in cocaine users with myocardial ischemia. Phentolamine reverses the effects of cocaine on the myocardium (decreases heart rate and blood pressure, increases coronary artery diameter, improves coronary flow). Although its mechanism of action seems ideal, phentolamine has a limited clinical use because of its side effects and short half life [8].

Beta-blockers are contraindicated in cocaine users. Although their use in patients with myocardial ischemia who are not using cocaine has numerous advantages (decreases mortality and the risk of further cardiovascular events) the same cannot be said for cocaine users. In these patients, the lack of an opposing alpha effect may lead to the inhibition of concurrent vasodilation, leading to aggravation of coronary spasm and hypertensive crisis. Studies conducted on dogs with acute cocaine toxicity showed that propranolol worsened the seizure threshold and caused death $[8,20]$. Esmolol elevates blood pressure levels, labetalol and carvedilol have few advantages as they block both $\alpha$ and $\beta$ receptors. Metoprolol increases the risk of death in cocaine users $[8,22]$.

Other pharmacological agents such as angiotensin-converting enzyme inhibitors, angiotensin receptors blockers, statins and diuretics have not been well studied, but are not expected to counteract cocaine effects [8]. Morphine can reverse cocaineinduced vasoconstriction. Dexmedetomidine, a central sympatholytic, can prevent the elevation of blood pressure levels, heart rate and sympathetic activity induced by cocaine [8].

Primary percutaneous angioplasty and thrombolysis should be considered in cocaine users with chest pain and ST segment elevation. There is an increased risk of intra-stent thrombosis in these patients (5-7.6\%) [8]. Fibrinolytic therapy is an acceptable alternative when primary angioplasty cannot be performed.

In the case of cocaine-induced cardiomyopathy the most efficient therapy is illicit drug cessation. The same is true to obtain improvement of heart failure symptoms. Use of $\beta$-blockers requires extreme caution and should be applied only after a detailed analysis of each case. Continued cocaine use may lead to loss of eligibility for cardiac transplant in case of patients with dilated cardiomyopathy [8]. 
Ventricular arrhythmias which may appear with acute use of cocaine due to sodium channel blockade should be treated with sodium bicarbonate. When ischemia is the probable mechanism it should be treated accordingly. Lidocaine should be used with caution, as in specific circumstances it may potentiate the toxic effect of cocaine on the central nervous system. Class III antiarrhythmic drugs should be used with caution because they can aggravate the cocaine induced QT interval prolongation.

\section{Stroke}

Statistics show that cocaine abuse is an independently risk factor for stroke. In active cocaine users there is a high frequency of hemorrhagic stroke. There is a slight increased risk of subarachnoid hemorrhage due of arterial aneurisms [8]. Tissue plasminogen activator has been used in patients with stroke without complications [23].

\section{OPIATES}

The term refers to substances of natural or synthetic origin that act on one of the three opioid receptors: $\mu, \mathrm{k}, \delta$. Opioids can cause analgesia, may depress the central nervous system or may cause euphoria.

Opioids include alkaloids extracted from the poppy plant - morphine and codeine - and semisynthetic derivatives. The term does not include the synthetic derivatives like oxycodone and methadone. Morphine like other opioids can be prescribed for pain relief.

Heroine - a morphine derivative - is the opioid most commonly used injectable. Opium extracted from the poppy plant is administered by smoking.

There are also a number of opioid derivatives used in medical practice due to their analgesic effect: oxycodone, hydrocodone (Vicodin, Lortab), meperidine and fentanyl. Used for non-medical purposes they may cause addiction.

Clinical manifestations in opioid users include infectious processes: cellulitis, abscesses at the place of venous puncture, endocarditis, osteomyelitis. There is also a high risk of HIV infection, hepatitis $\mathrm{B}$ or $\mathrm{C}$ secondary to administration in nonsterile conditions. Endocarditis usually involves the tricuspid valve. Opioid-addicted users complain of pain with various locations (secondary to hyperalgesia) or narcotic bowel syndrome, a condition in which the patient complains of abdominal pain and requires increasingly higher opioid doses.

Unspecific changes have been described in the myocardium: coronary atherosclerosis, fibrosis, cardiomyopathy (toxic, post-myocarditis) but cannot be linked exclusively to morphine or heroine, mainly because studied patients proved multidrug abuse [10]. Morphine increases the production of nitric oxide [24] and of COX2, having a cardioprotective effect on ischemia-reperfusion lesions [25].

\section{CANNABINOIDS (MARIJUANA, HASHISH)}

Cannabis is the most frequently used illicit substance in the world. Statistics estimate that approximately 160 million people aged 15 to 64 years old have used cannabis at least once in their life [1]. These substances are obtained from Cannabis sativa. The dried leaves and flowers are called marijuana, and the dried resin from the flower's surface is called hashish. This drug is usually smoked and rarely ingested. Symptoms (somnolence, euphoria, increased sensory perception, time and space distortion, feeling of unreality) usually last approximately two to four hours. Common effects of marijuana are: mild tachycardia, orthostatic hypotension, bronchodilation, hyperemic conjunctiva, and disturbed motor coordination. The effects of marijuana are dose dependent. It is not clear if marijuana induces accelerated atherosclerosis of coronary arteries. Observations show that when comparing marijuana users to non-users the relative risk for myocardial infarction in patients with ischemic coronary artery disease increases after drug use to 4.8 fold in the first 60 minutes, 1.7 fold in the second hour, and then returns to equal levels.

The effects of marijuana are mainly due to a psychoactive component - tetrahydrocannabinol that binds to a central specific receptor. There is no antidote for cannabinoids. An antioxidant - acetylcysteine, antidepressants (bupropion and nafazodone), anticonvulsants (gabapentin $1200 \mathrm{mg} /$ day) and cannabinoid agonists (delta - 9 tetrahydrocannabinol $10 \mathrm{mg}, 5$ times daily) have been used to improve symptoms induced by cannabinoids.

\section{AMPHETAMINES}

The class of amphetamines includes a large category of derivatives from phenylethylamine, 
such as methamphetamine, methylphenidate (Ritalin) and methylenedioxymethamphetamine (MDMA Ecstasy). Amphetamine increases the release of catecholamines, blocks their reuptake and interacts directly on the catecholamine receptors. Some amphetamine metabolites inhibit monoamineoxidase resulting in an increase of plasma concentration of norepinephrine. Other derivatives may cause serotonin release, acting from the central receptors of serotonin.

Histologically, the effects of amphetamines are similar to those of cocaine: hypertrophy, interstitial fibrosis, microvascular disease (hypertrophy of media of the arteries). Accelerated atherosclerosis has been observed and linked to amphetamines, but their use is frequently associated with the use of other drugs or with smoking [10]. Amphetamines induce calmodulin activation, increase the levels of thermic shock proteins, inhibit monoamine-oxidase and norepinephrine re-uptake.

MDMA, also known for its use in drugfacilitated sexual assaults, has sensorial effects such as alteration of color intensity or of the perception of textures, euphoria, disinhibition and sexual arousal. The increased use of MDMA led to numerous serious complications and death. Clinical manifestations in case of MDMA abuse are:

- Cardiovascular stimulation and cardiac toxicity which may include severe arterial hypertension, myocardial infarction, aortic dissection, and arrhythmias. Hemorrhagic stroke may also occur.

- Myocardial infarction occurs less in MDMA users compared to cocaine users and may be due to coronary atherosclerosis but also to vasospasm. Chest pain in MDMA users must be evaluated similarly to the chest pain in case of cocaine abuse. Benzodiazepines, aspirin, nitroglycerin, oxygen should be administered. Beta-blockers are not recommended.

- Tako-tsubo cardiomyopathy in case of metamphetamine use has first been reported in 2007. Mechanisms possibly involved are catecholamine-mediated cardiac toxicity, microvascular disease, coronary spasm, reduced metabolism of fatty acids [10].

- The mechanism of aortic dissection is not completely understood. The elevated plasmatic and tissue concentrations of catecholamines lead to endothelial lesions in large and small vessels through the effects of free radicals: o-quinone (aminochrome, dapachrome, adrenochrome, noradrenochrome).

- Severe arterial hypertension is secondary to both central and peripheral mechanisms. The central mechanism can be antagonized with sedatives, benzodiazepines (diazepam). If blood pressure control cannot be achieved, sodium nitroprusside or $\alpha$-adrenergic blockers (phentolamine) should be administered. Beta-blockers are not recommended because they increase coronary spasm and mortality.

- Catecholamine excess, cardiac remodeling (hypertrophy, fibrosis) and ischemia (atherosclerosis, microvascular disease) predispose to arrhythmias. Supraventricular tachyarrhythmias should be treated with adenosine or calcium channel blockers.

- Other clinical manifestations are psychomotor agitation, hyperthermia, hyponatremia, serotonin syndrome (autonomic dysfunction, abnormal neuromuscular activity, and altered mental status), and disseminated intravascular coagulation.

\section{OTHER HALLUCINOGENS}

The popularity of these drugs reached its peak in the 1960s. From the 1980s these drugs became popular again in the young population. They refer to LSD, psilocybin, phencyclidine, and mescaline.

LSD (lysergic acid diethylamide) is the most potent hallucinogen which acts as a 5HT2 (5 hydroxytryptamine). LSD produces sympthomimetic symptoms (important mydriasis, increases in heart rate, elevated blood pressure and temperature). In case of excessive sympathomimetic stimulation, benzodiazepines should be administered, and if necessary an additional sedative like haloperidol.

Psilocybin is structurally related to LSD. The onset of the symptoms begins approximately 30 minutes after ingestion of psilocybin containing mushrooms and the hallucinogen effect lasts for four to six hours. Common effects are mydriasis, mild tachycardia, hyperreflexia, nausea and vomiting. Hyperthermia appears rarely [26].

Mescaline is structurally related to amphetamines. Mescaline acts as a 5-HT agonist, being much weaker than LSD. Mescaline effects are abdominal discomfort, diaphoresis, vertigo, nystagmus, ataxia, mydriasis, mild increase in heart rate, blood pressure and temperature. Death may occur after aberrant behavior under the influence of the drug [26].

Phencyclidine is a synthetic derivative of piperidine, structurally related to ketamine. Phencyclidine acts as a glutamic antagonist of $\mathrm{N}$-methyl-D-aspartate receptors (NMDA). Clinical manifestations are myosis, nystagmus, blood pressure elevations, sympathomimetic symptoms, 
anticholinergic and cholinergic effects. Medical complications are common and consist of inducing coma $(10.6 \%)$, seizures $(3.1 \%)$, elevated creatinekinase levels with or without acute renal failure, hypoglycemia, cerebral hemorrhage due to elevated blood pressure, and hyperthermia. The treatment is based on supportive measures and specific treatments of the possible occurring complications [26].

Bufotenin (5-HO-DMT, N,N-dimethylserotonin) is a tryptamine related to serotonin. It is an indole alkylamine with hallucinogenic effects. It may be found in compounds also containing toxic cardioactive steroids with digoxin-like properties, thus provoking severe toxic reactions and even death. Its name originates from the Bufo genus of toads, which includes several species of psychoactive toads (most notably Incilius alvarius) that secrete it from their parotid glands. The administration of specific Fab antibodies for digoxin may be life-saving in patients poisoned with toad venom [26].

Ketamine is an NMDA receptor antagonist acting also on other sites (opioid receptors, monoamine transporters) [27]. It is a dissociative agent such as phencyclidine, and was first developed in 1962. Apart from its major medical use for starting and maintaining anesthesia, ketamine emerged as a recreational drug in the early 1970 s and there have been reports of its use in drug-facilitated sexual assaults. Industrial-scale illicit ketamine is hard to achieve due to its complexity of synthesis. It exerts a direct dose-dependant negative inotropic effect on the myocardium leading to decreased contractility and heart rate and elevated blood pressure levels [28]. There is no known effective antidote to treat ketamine overdose, and thus therapy focuses on maintenance of respiratory and circulatory function.

\section{CONCLUSION}

Illicit drugs have significant cardiovascular side effects, which have to be known by the clinician in order to optimize the therapeutic management.

Conflict of interest: none declared.

Utilizarea drogurilor a crescut alarmant în ultimii ani. Astfel că numărul de prezentări în cadrul departamentelor de primiri urgență datorate efectelor adverse ale acestora a crescut şi el. Acest articol tip review discută efectele asupra sistemului cardiovascular al cocainei, opioidelor, canabinoidelor, metamfetaminelor şi halucinogenelor deoarece clinicianul trebuie să le cunoască, să le ințeleagă mecanismul fiziopatologic pentru a îmbunătăți abordarea terapeutică.

Correspondence to: Mihaela Hostiuc, "Floreasca" Clinical Emergency Hospital,

Department of Internal Medicine, Calea Floreasca nr.8, Bucharest

Tel.: 0726347183

E-mail: mihaela_constantinescu_ms@yahoo.com

\section{REFERENCES}

1. www.drugwarfacts.org

2. WILBERT-LAMPEN U, SELIGER C, ZILKER T, ARENDT RM. Cocaine Increases the Endothelial Release of Immunoreactive Endothelin and Its Concentrations in Human Plasma and Urine: Reversal by Coincubation With $\sigma$-Receptor Antagonists. Circulation 1998, 98(5):385-390.

3. MO W, SINGH AK, ARRUDA JAL, DUNEA G. Role of Nitric Oxide in Cocaine-Induced Acute Hypertension. American Journal of Hypertension 1998, 11(6):708-714.

4. LANGE RA, HILLIS LD. Cardiovascular Complications of Cocaine Use. New England Journal of Medicine 2001, 345(5):351-358.

5. HEESCH CM, WILHELM CR, RISTICH J, ADNANE J, BONTEMPO FA, WAGNER WR. Cocaine activates platelets and increases the formation of circulating platelet containing microaggregates in humans. Heart 2000, 83(6):688-695.

6. RINDER HM, AULT KA, JATLOW PI, KOSTEN TR, SMITH BR. Platelet alpha-granule release in cocaine users. Circulation 1994, 90(3):1162-1167.

7. SIEGEL AJ, MENDELSON JH, SHOLAR MB, MCDONALD JC, LEWANDROWSKI KB, LEWANDROWSKI EL, LIPINSKA I, RIDKER PM, TOFLER GH. Effect of cocaine usage on C-reactive protein, von Willebrand factor, and fibrinogen. American Journal of Cardiology, 89(9):1133-1135.

8. SCHWARTZ BG, REZKALLA S, KLONER RA. Cardiovascular Effects of Cocaine. Circulation 2010, 122(24):2558-2569.

9. GUO J, GANG H, ZHANG S. Molecular Determinants of Cocaine Block of Human Ether-á-go-go-Related Gene Potassium Channels. Journal of Pharmacology and Experimental Therapeutics 2006, 317(2):865-874. 
10. KARCH SB. The pathology of drug abuse. CRC Press Boca Raton; 1996.

11. QURESHI AI, SURI MFK, GUTERMAN LR, HOPKINS LN. Cocaine Use and the Likelihood of Nonfatal Myocardial Infarction and Stroke: Data From the Third National Health and Nutrition Examination Survey. Circulation 2001, 103(4):502-506.

12. HOLLANDER JE, HOFFMAN RS. Cocaine-induced myocardial infarction: An analysis and review of the literature. Journal of Emergency Medicine, 10(2):169-177.

13. MOHAMAD T, NIRAJ A, FARAH J, OBIDEEN M, BADHEKA A, KONDUR A, THATAI D, AFONSO L. Spectrum of electrocardiographic and angiographic coronary artery disease findings in patients with cocaine-associated myocardial infarction. Coronary artery disease 2009, 20(5):332-336.

14. HOLLANDER JE, HOFFMAN RS, BURSTEIN JL, et al. Cocaine-associated myocardial infarction: Mortality and complications. Archives of Internal Medicine 1995, 155(10):1081-1086.

15. HSUE PY, SALINAS CL, BOLGER AF, BENOWITZ NL, WATERS DD. Acute Aortic Dissection Related to Crack Cocaine. Circulation 2002, 105(13):1592-1595.

16. DEAN JH, WOZNICKI EM, O'GARA P, MONTGOMERY DG, TRIMARCHI S, MYRMEL T, PYERITZ RE, HARRIS KM, SUZUKI T, BRAVERMAN AC et al. Cocaine-related Aortic Dissection: Lessons from the International Registry of Acute Aortic Dissection. The American Journal of Medicine, 127(9):878-885.

17. EAGLE KA, ISSELBACHER EM, DESANCTIS RW, INVESTIGATORS tIRfAD. Cocaine-Related Aortic Dissection in Perspective. Circulation 2002, 105(13):1529-1530.

18. CHAMBERS HF, MORRIS DL, TÄUBER MG, MODIN G. Cocaine Use and the Risk for Endocarditis in Intravenous Drug Users. Annals of Internal Medicine 1987, 106(6):833-836.

19. BRECKLIN CS, GOPANIUK-FOLGA A, KRAVETZ T, SABAH S, SINGH A, ARRUDA JAL, DUNEA G. Prevalence of Hypertension in Chronic Cocaine Users. American Journal of Hypertension 1998, 11(11):1279-1283.

20. CATRAVAS JD, WATERS IW. Acute cocaine intoxication in the conscious dog: studies on the mechanism of lethality. Journal of Pharmacology and Experimental Therapeutics 1981, 217(2):350-356.

21. BROGAN IIIWC, LANGE RA, KIM AS, MOLITERNO DJ, HILLIS LD. Alleviation of cocaine-induced coronary vasoconstriction by nitroglycerin. Journal of the American College of Cardiology 1991, 18(2):581-586.

22. SOFUOGLU M, BROWN S, BABB DA, PENTEL PR, HATSUKAMI DK. Carvedilol affects the physiological and behavioral response to smoked cocaine in humans. Drug \& Alcohol Dependence, 60(1):69-76.

23. MARTIN-SCHILD S, ALBRIGHT KC, MISRA V, PHILIP M, BARRETO AD, HALLEVI H, GROTTA JC, SAVITZ SI. Intravenous Tissue Plasminogen Activator in Patients with Cocaine-Associated Acute Ischemic Stroke. Stroke; a journal of cerebral circulation 2009, 40(11):3635-3637.

24. AFSHARI R, MAXWELL SRJ, WEBB DJ, BATEMAN DN. Morphine is an arteriolar vasodilator in man. British Journal of Clinical Pharmacology 2009, 67(4):386-393.

25. LIU C, DAI R, YU R, XU J. Morphine preconditioning, cardioprotection and left ventricular remodelling in rabbits. Acta Cardiol 2011, 66(3):341-348.

26. TINTINALLI JE, STAPCZYNSKI JS. Tintinalli's emergency medicine: a comprehensive study guide. McGraw-Hill, New York; 2011.

27. KOHRS R, DURIEUX ME. Ketamine: Teaching an old drug new tricks. Anesthesia \& Analgesia 1998, 87(5):1186-1193.

28. SPRUNG MDPJ, SCHUETZ BSSHANNON M, STEWART MDROBERT W, MORAVEC PCHRISTINE S. Effects of ketamine on the contractility of failing and nonfailing human heart muscles in vitro. The Journal of the American Society of Anesthesiologists 1998, 88(5):1202-1210.

Received May 312015 